\title{
Collective Learning in the Workplace: Important Knowledge Sharing Behaviours
}

\author{
$\underline{\text { http://dx.doi.org/ijac.v4i4.1801 }}$ \\ Allison Littlejohn, Colin Milligan and Anoush Margaryan \\ Caledonian Academy, Glasgow Caledonian University, United Kingdom
}

\begin{abstract}
In this paper we identify a set of learning practices adopted by knowledge workers as they learn at work. We examine how key knowledge sharing behaviours: consuming, connecting, creating and contributing knowledge, are associated with these learning practices. Each learning practice brings together a combination of these components to form a distinct learning pathway, providing a baseline for rethinking combinations of practices for more effective learning and development in the workplace.
\end{abstract}

Keywords_-knowledge, sharing, learning, development, workplace

\section{Collective KnOWledge Practices}

A major source of competitive advantage for companies is knowledge (Lundvall, Rasmussen and Lorenz, 2008)[1]. Knowledge is an essential component to complete the sorts of increasingly complex tasks employees face that require flexible responses which could not have been anticipated (Nardi, Whittaker and Schwarz, 2000)[6].

To be able to access and use the best knowledge assets wherever they reside in the world, employees must be able to work together within groups, networks and with the collective (IBM, 2009) [2]. Yet this cooperation is dependent on the processes of discovery, synthesis and sharing of knowledge which are complex in themselves.

In recent years there has been a shift in the literature and in the conceptual debates about what constitutes learning. The view of learning has moved from from individual problem solving (Schmidt, Norman \& Boshuizen, 1990) [3] to knowledge building negotiated with others around work tasks (Paavola and Hakkarainen, 2005; Engeström \& Middleton, 1996) [4][5]

A number of empirical studies have identified the importance of collective knowledge building to workplace learning. An early study by Lorenz (1996) [10] identified the 'creation and further development of a base of common or shared knowledge' as important for collective learning in the workplace (Lorenz, 1996). Central to collective learning is the constant updating and upgrading of the knowledge base through the acquisition of external knowledge, the creation and dissemination of new knowledge [11] (Stankevicuite and Jucevicius, 2000).

Davenport (2005) [12] proposed a typology of knowledge workers, segmenting their behaviours as finding, creating, packaging, distributing and applying knowledge. Similarly, Dorsey (2000) [13] outlined a set of seven distinct actions related to use of knowledge: retrieving, evaluating, securing and organizing information as well as analysing, collaborating around and re-presenting knowledge. Sellen, Murphy and Shaw (2002) [14] also describe a range of collective knowledge behaviours as browsing, finding information and resources, communicating with others, information gathering and housekeeping and transacting with others.

An ethnographic study examining employees' knowledge management practices identified the following behaviours: scanning and finding information; networking and collaborating with other people; organising and improving information (Karrer, 2008) [15]. These activities are similar to the collective knowledge behaviours of experts and novices identified by the authors during an in depth study of learning practices within a large, multinational organisation. (Margaryan, Milligan, Littlejohn, Hendrix and Graeb-Konneker, 2009; Margaryan, Littlejohn and Milligan, 2009a; Margaryan, Littlejohn and Milligan, 2009b) [16] [17] [18]. The range of behaviours observed in this study can be summarise by the statement: in the workplace, individuals consume, connect, create and contribute to the collective knowledge. To consume collective knowledge, individuals need to be able to identify and source knowledge residing within the collective. To enable him/her to find relevant knowledge, the knowledge base must be transparent and accessible. The individual continually elaborates and refines his/her view of the collective knowledge by connecting to knowledge resources, people, discussions and other knowledge bases. $\mathrm{He}$ or she may also contribute to the collective knowledge, through creating, sharing and feeding knowledge back into the collective. These four knowledge behaviours - connecting, consuming, creating and contributing to the collective knowledge - are intertwined activities rather than discrete linear steps.

While these initial conceptualisations are useful, there is still limited understanding of how the exchange and coconstruction of knowledge contributes to learning in the workplace. This study aims to extend our understanding of contemporary workplace learning practices and align these practices to specific knowledge sharing behaviours the ways employees create and disseminate knowledge. We start by identifying the learning practices of knowledge workers. Then we analyse these practices to identify precise knowledge sharing behaviours within each of these practices. Finally we identify which amalgamations of knowledge sharing behaviours form discreet learning pathways and how these combinations are likely to lead to effective learning in the workplace.

\section{METHOD}

In this study we investigated the learning practices of knowledge workers employed within a large, multinational organisation. Participants were members of a number of global, online knowledge sharing networks focused 
PAPER

around the core technical and commercial disciplines of the company. Membership of each network ranged from a few hundred to a few thousand professionals at various stages of their career. Members used the online networks to exchange knowledge and discuss problems and solutions.

Data were collected through a mixed methods approach involving a web-based questionnaire survey followed by semi-structured interviews. The quantitative survey was designed to provide an overall picture of the study sample. It was based on an existing survey instrument (Cross and Parker, 2004) [19]. The survey was complemented by an in depth qualitative investigation with a sub-sample of respondents. The qualitative study followed the quantitative study and data collected in the quantitative phase informed the design of the qualitative instrument.

The survey instrument was adapted and extended to include several additional factors that we identified as important for the purposes of this study (choice of tools for knowledge sharing, experience level, ways in which individuals draw upon and contribute to the wider knowledge pool within and beyond the company). The instrument was adapted in collaboration with the company research partners and the coordinators of the knowledge sharing networks. It was tested by the network coordinators and others in the company $(\mathrm{n}=25)$ as well as piloted with a small sample $(n=37)$ from a single global network community. These trials allowed refinement of the instrument. Reliability analysis confirmed good internal consistency $(\alpha=.88)$. The survey was delivered using SurveyMonkey (www.surveymonkey.com) and is available online at http://dl.dropbox.com/u/6017514/survey.pdf. A link to the survey was posted on the discussion fora of six networks, and the mailing list of a seventh, a Graduate Network, which does not utilise a discussion forum. Members of these networks were invited to complete the survey through messages posted by network coordinators. The survey was open for four weeks between September and November 2008.

Recruiting respondents for the survey through the knowledge sharing networks introduces a significant, if unavoidable sampling bias. These networks are large (with a combined membership of more than 30.000 members across the networks included in the current analysis), but only a fraction of users are active and the link to the survey is likely to have been seen by only the most active members of these communities. The fraction who have accessed and responded to the survey has representation from all geographic locations, a broad range of job profiles, and all experience levels, which suggests that it is broadly representative if somewhat skewed towards the active population of these networks.

After completing the survey, respondents were asked if they would volunteer for a follow-up interview. These semi-structured interviews sought to elicit information about the ways in which experts and novices define and pursue their learning and development goals, how they draw upon and contribute to the collective knowledge in the process of learning and working, what they learn, what learning methods the use and who they learn with. The interview script is available online at: http://dl.dropbox.com/u/6017514/interviewscript.pdf. Follow-up interviews were conducted by telephone, and lasted for up to one hour. Informed consent was sought prior to data collection (separately for the survey and interview).

The results reported in this paper are based on the total of 462 survey respondents, including 211 (45.7\%) experts, $128(27.7 \%)$ mid-career professionals and $123(26.6 \%)$ novices. 139 respondents volunteered for interview and from these, 29 interviews were conducted (nine novices, and twenty experts). In this study, we define as experts those who have 10 or more years of experience, midcareer as those who have between 4 and 10 years of experience and novices as those who have up to 3 years of experience in their discipline. The data analysis did not uncover major differences between experts and midcareer professionals: midcareers practices are more like those of experts than novices. Therefore, for the purposes of this analysis, we combined expert and midcareer responses.

We acknowledge potential problems with a definition of expert and novice, which considers merely the quantity rather than quality of experience which is a core aspect in current conceptualisations of expertise (Ericsson et al, 2006) [20]. Obtaining objective measures of expertise level, such as performance appraisal information, was unfeasible for this study. Instead, for each respondent, researchers triangulated the data on the years of experience in their specialism with the number of years they had spent with the company and their time in their current role. We compared these data with respondents' perception of their status as experts (did they consider themselves expert and did they feel they were considered experts by their peers).

Survey data was tabulated and analysed using SPSS 16.0. Interview data was transcribed and coded using NVivo 8. For the qualitative analysis, an initial set of conceptual codes were defined and refined through four iterations. All interviews were coded by a single researcher to ensure consistency. Coding for a sample of interviews was cross-checked by two further researchers to determine consistency. The following section details the learning practices identified through the analysis and outlines the knowledge behaviours associated with each.

\section{LEARNing PRACTICES AND ASSOCIATED KNOWLEDGE BEHAVIOURS}

To understand the range of learning practices which were present in our study population, we asked participants to think about their most significant learning experience over the past year, focusing on how they had learned (what learning methods they used). Our analysis identified seven distinct learning practices covering a range of formal and informal learning approaches: (i) formal learning (classroom or blended learning courses), (ii)self-study (e.g. reading literature or self-paced e-learning), (iii) learning through discussions with others, (iv) learning through experience, (v) vicarious learning, (vi) mentoring and coaching and (vii) learning by teaching others (Table 1). Formal learning and learning through experience emerged as important forms of learning for the majority of the interviewees, both experts and novices. Novices place more value on formal and experiential learning, with all nine respondents reporting these as important forms of learning. The trends of novices and experts in terms of the types of learning practice they find helpful tend to be broadly the same, though novices may have been more sensitized to what might constitute learning that experts. 
PAPER

The reason for this could be because many novices had only recently left fulltime education.

One of the most striking outcomes of the analysis was that all respondents reported that they had learned in more than one way. Typically their learning practices involved a combination of knowledge sharing behaviours. This interdependency of different learning practices and knowledge sharing behaviours agrees with Billet's [3] assertion that workplace tasks are dynamic and interdependent.

Respondents' formal learning was typically participation within structured courses run by the organisation. This type of formal learning was valued by most respondents, whether expert or and novice, with one expert commenting: "Formal courses are good and it is fantastic to have reference books as well that you can refer to when required" (Expert, Community 1 ).

The social dimension of courses, for example collaborating with other people, linking with the collective and so on, proved to be major motivators for participating in these traditional forms of learning. We found evidence that respondents viewed formal courses as a means of meeting and interacting with people across the organization. When enrolling for a course, respondents had a broad range of intentions. For some, their primary purpose was to connect with other people from across the organization. For others, the main reason for enrolling in a course was to connect with and use prescribed knowledge and information resources. For a few the main aim was to gain accreditation and that, for them, was the primary value in formal learning.

Novices and experts said that they benefitted from meeting different types of colleagues at various stages of their careers. Some respondents valued the opportunity to meet others 'working at a similar level' and with ' related aspirations'. Meeting with other people in the organisation provided novices with an opportunity to develop their networks. Novice respondents seemed to appreciate "meeting people from different parts of the company" (Novice, Community 1) during formal course sessions. Meeting with other people in the organisation provided these novices with an opportunity to develop their networks within the organisation.

Formal learning also offers an opportunity to extend networks beyond the organisation. Courses, provided by external organisations rather than by the corporate training centres of the company, provided our respondents with opportunities to meet people from other companies and industries, giving them opportunity to grow their external networks.

Our data provided evidence that formal courses did not always lead to effective learning. Respondents reported that courses could, at times, be de-motivating. Some were very critical of the pedagogy behind formal courses. One novice commented on the inefficiency of some formal learning practices: "I find that classes are very inefficient. Something I find alarming is the reliance on very passive learning techniques such as PowerPoint presentations. Retention of information is very, very low. (Novice, Community 1).

From the data, we identified a number of knowledge behaviours carried out by respondents during formal learning: connecting with and consuming knowledge from knowledge resources and from other people.
Learning through experience was viewed by the majority of our respondents as an important form of learning. For them, experiential learning involves working on reallife projects and tasks, collaborating with others and daily problem-solving. Experts and novices alike indicated that it was only through participation in work-based projects that they could make sense of their learning and fully appreciate the knowledge and skills that they had developed. They built up their knowledge base mainly through connecting with people with "different levels of knowledge and depth of experience."

Most respondents reported that they engage in different learning practices at the same time. For some respondents, experiential learning is a natural follow-on from formal learning.

The value of linking formal learning with experiential practice cannot be underestimated. Respondents found it useful to participate in a formal course then immediately apply what they have learned learning within a real-world project. The course serves as a baseline, while the real-life task allows for practice and consolidation of knowledge. As one responded observed: "The course prepared me. Without the course I wouldn't have any idea before I started off in the project. That wouldn't be a very good thing but again the learning was complete because of the working that I actually had, the experience." (Expert, Community 2).

One respondent commented on the importance of putting knowledge gained through formal learning into practice when he commented: "I went on four courses when I joined [the organization]. Very useful then, but I forgot all of it and it is only when I started working with it and I remember oh I have used a formula like that before or I know how to do that." (Novice, Community 6).

Experiential learning was challenging for novices, some of whom described on-the-job learning experiences as "sink or swim" situations. By completing challenging tasks successfully, some novices developed confidence in their ability to learn quickly and to perform well under stressful conditions. We found evidence that some novices actively sought out challenging projects with steep learning trajectories. One novice recognised that he benefitted from "Being thrown into the deep, a quite complex start". (Novice, Community 6).

Experiential learning was the only form of learning practice where we found evidence of all four knowledge behaviours taking place concurrently. Knowledge sharing behaviours associated with learning through experience include connecting with, consuming, creating and contributing knowledge to the collective.

Learning through discussions was also important for our respondents. Experts and novices alike valued connecting to and sharing knowledge with others. Discussions provided them with a support mechanism for coping with work. Respondents reported that, in addition to being a valuable form of learning at work, dialogue with others helped them function more effectively within the organization in their daily work practice.

Novices valued discussions with more knowledgeable colleagues. But they also viewed close interactions with peers as an important. One novice summed it up by observing: "You go much more to your peers and try to extract knowledge from other people, actively looking for 
PAPER

other people who you think have a certain amount of knowledge." (Novice, Community 6).

Experts valued learning through discussions. One expert described dialogue with experienced colleagues as an optimal learning practice when he said: "For me... the biggest way to learn is to sit alongside people who know what they are doing or can help you do what you do a bit better and get on and do it." (Expert, Community 3).

Out respondents said that they learned through conversations with a wide range of colleagues with different roles: peers, mentors, coaches, managers or people from other parts of the organisation or from outside the company. For them, one important feature of learning through discussion was the immediacy of the interaction. Discussions might range from "one-on-one" to group discussions. Most respondents favoured face-to-face dialogue over technology mediated discussions. However face-toface interaction were not always possible, particularly when colleagues are distributed around the world. Consequently meetings and co-working were frequently mediated by technology.

Respondents reported that one advantage of technology mediated discussions and interactions was that they could be recorded so that the knowledge generated during work tasks could be contributed back to the collective. However there is little evidence of this happening. The reason could be due to the complexity of discussions and interaction, which makes it difficult for others to pinpoint useful pieces of knowledge embedded within lengthy discussions. Another reason could be that many technologymediated discussions are facilitated through 'closed' technology systems, such as email. The closed nature of email inboxes are the primary reason why information is not reused and contributed back to the collective.

Respondents noted that the knowledge behaviours associated with learning through discussions were connecting with and consuming the knowledge of others through face-to-face or technology mediated interactions.

Learning through mentors and coaches offered respondents opportunity to learn through connecting to a range of other people. Although mentoring and coaching is usually one-on-one, one expert was involved in an informal, self-organised mentoring circle with colleagues from across the organisation. This sort of collective mentoring was viewed as a valuable way of providing mutual support and networking.

Some respondents viewed having a mentor or coach from outside their own department as important. They believed that working with mentors and coaches from outside their immediate team allowed for an 'outside perspective' and increased the objectivity of the mentor's feedback. One respondent commented on the difference between discussing problems with his supervisor and learning from a mentor from outside the organisation: "My supervisor always has an agenda [in mind]... but someone who is completely outside of that business can really be objective." (Expert, Community 4).

Mentoring and coaching include the key behaviours of connecting with others while consuming and contributing knowledge.

Learning by teaching others was reported by respondents as a complement to coaching and mentoring. One novice emphasised the importance of learning by teaching others when he commented: "Teaching to me is the ulti- mate way of learning because you have to force yourself to articulate it and you begin to learn where your gaps of knowledge are especially when the person you are teaching asks you a question and should know and you don't." (Novice, Community 1).

Teaching others allows for a bidirectional flow of knowledge and experience: not only did novices learn from experts, but, conversely, experts learned from novices. One expert described how he learned from new graduates: "These were high potential graduates and I definitely learned a thing or two from them." (Expert, Community 5).

Respondents described knowledge behaviours associated with learning by teaching others as connecting and contributing knowledge.

Vicarious learning involves observing other people performing work tasks and learning from their actions and mistakes. Four respondents reported vicarious learning as an important form of workplace learning. One respondent described vicarious learning as "the most significant form of learning in the workplace" (Expert, Community 3). Vicarious learning was reported more frequently by novices rather than experts. One reason could be that were more sensitized to what might constitute learning. Alternatively novices may perceive they learn by observing more experienced colleagues. However, we also found evidence (several examples) of experts learning from novices. A key knowledge practice associated with vicarious learning is connecting with other people.

Self-study was another key learning practice that surfaced in this study. Important forms of self-study described by respondents included reading staff magazines, trade journals as well as various internal resources (strategy updates, senior executives' speeches), in order to stay informed. 'Diving into the literature' is important, particularly for expert knowledge workers who indicated that formal training would have to be supplemented by studying original research papers.

Some respondents reported problems dealing with large quantities of knowledge and information. Others had developed effective strategies for connecting to relevant resources, for example selecting resources through peer recommendations: "I have five reports and I read only four... because only two or three of the [company] people have read [one]." (Novice, Community 1 ).

Self-paced e-learning courses also offer opportunities for self-study but were not universally popular. This could be because the e-resources do not allow for rich interaction with other people.

Two experts were particularly negatively about elearning self-study: "[e-learning resources] are generally a one hour session with a bunch of slides... If you are lucky you get some audio recordings to go with it. Some of them are even without that. I find them not a very exciting way of learning." (Expert, Community 1). "All this virtual stuff I don't think is particularly productive. There is assumed interaction and you can ask questions, but that is just exchanging statements, that [is] not true interaction." (Expert, Community 5).

Respondents reported that self-study tended to focus on one specific knowledge behaviour: consuming knowledge from different types of resources. Other knowledge behaviours associated with self-study are connecting with and consuming information sources. 
PAPER

COLLECTIVE LEARNING IN THE WORKPLACE: IMPORTANT KNOWLEDGE SHARING BEHAVIOURS

TABLE I.

LEARNING PRACTICES AND ASSOCIATED KNOWLEDGE BEHAVIOURS

\begin{tabular}{|c|c|c|c|c|c|c|c|}
\hline Learning practice & Response & Novice & Expert & Connect & Consume & Create & Contribute \\
\hline Formal learning & $25 / 29$ & $9 / 9$ & $16 / 20$ & $\mathrm{X}$ & $\mathrm{X}$ & - & - \\
\hline Learning through experience & $20 / 29$ & $9 / 9$ & $11 / 20$ & $\mathrm{X}$ & $\mathrm{X}$ & $\mathrm{X}$ & $\mathrm{X}$ \\
\hline Learning through discussing with others & $10 / 29$ & $4 / 9$ & $6 / 20$ & $\mathrm{X}$ & $\mathrm{X}$ & - & - \\
\hline Learning through mentors or coaches & $7 / 29$ & $4 / 9$ & $3 / 20$ & $\mathrm{X}$ & $\mathrm{X}$ & - & - \\
\hline Learning through teaching others & $6 / 29$ & $3 / 9$ & $3 / 20$ & - & - & $\mathrm{X}$ & $\mathrm{X}$ \\
\hline Vicarious learning & $4 / 29$ & $1 / 9$ & $3 / 20$ & $\mathrm{X}$ & $\mathrm{X}$ & - & - \\
\hline Learning through self-study & $4 / 29$ & $3 / 9$ & $1 / 20$ & $\mathrm{X}$ & $\mathrm{X}$ & - & - \\
\hline
\end{tabular}

Table I summarises the seven learning practices reported, along with the knowledge behaviours that respondents identified as they described how they engaged in each learning practice. The Table also illustrates the number of respondents (novices and experts) who said each form of practice was important for him or her.

From our empirical data we have made a number of observations on how discreet knowledge behaviours are associated with these seven forms of learning practice.

First, we identified at least four types of knowledge behaviours underpinning workplace learning practices. This observation verifies learning practices observed in previous studies [15][16]. However, the significance of each knowledge action for effective learning is still unclear. A more thorough understanding of these learning practices and their associated knowledge behaviours would inform future workplace learning designs.

Second, knowledge behaviours tend to occur in pairs, with connecting - consuming and creating - contributing coupled together. Our findings suggest that learning may be more effective when knowledge behaviours are coupled. This observation is evidenced by the fact that respondents tend to talk about knowledge behaviours in pairs. For example the describe connecting and consuming - rather than consuming only. We acknowledge that more work is needed to confirm this finding, since our study is limited to allow us to make robust generalizations. Nevertheless these are the patterns we observed in our data.

These results agree with Karrer's [14] conceptual study of knowledge behaviours that suggested that employees may connect and consume knowledge resources, through finding and scanning information. Employees connect and consume knowledge through networking and collaborating with other people. The study also identified that employees create and contribute to collective knowledge through organising information, thereby creating new meanings and new knowledge. Combining behaviours could help individuals or organisations setting up personal learning and work environments: technology tools for connecting may be most effective when they interface with tools for consuming. Similarly technology tools for creating knowledge resources may be most effective when they interface with tools for contributing knowledge to the collective.

Third, workplace learning practices tend to include knowledge behaviours of connecting and consuming, but sometimes neglect creating and contributing. Knowledge building at work is integrated within work tasks, which means that, where work activities are collaborative, knowledge building will be with other people [3]. Although most of the workplace learning practices identified through this study were social practices, some did not encourage collaborative knowledge creation and Workplace learning is potentially more effective if tasks that involve the creation and sharing of knowledge are embedded within learning and work practices.

Fourth, only one learning practice (learning through experience) appeared to incorporate all four knowledge behaviours. Most respondents reported that learning through experience was the most effective learning practice. It is possible that learning pathways which incorporate all four knowledge sharing behaviours are potentially more powerful than those which incorporate a subset. Learning effectiveness may be optimised by using learning practices, or combinations of practices, that combine all four knowledge actions. Several respondents reported that formal learning (connecting and consuming knowledge) was more powerful when combined with experiential learning (connecting, consuming, creating and contributing knowledge). Formal learning could also potentially be strengthened when combined with teaching others (creating and contributing knowledge).

Finally, formal learning is generally acknowledged as learning, but other forms of learning are not always recognised as learning practices. When we asked interviewees to think about their most significant learning experience in the past year and how they learned, most people focused on formal learning, and they had to be further prompted by the interviewer to think about other forms of learning that they drew upon in the context of their daily work.

Respondents recognition of (internally facilitated) formal learning as the predominant learning practice may explain why learning practices tend to focus on internal activities within the organisation, rather than looking outside the company Learning in the workplace could be improved by incorporating the sorts of internal and external knowledge handling activities observed by Jarche (2010) [10] through which individuals seek, sense and share knowledge.

\section{CONCLUSIONS}

Our empirical study helped build an initial understanding of how discreet actions associated with collective knowledge building are associated with a broad range of learning practices in the workplace. Each learning practice brings together a combination of these knowledge actions. Understanding the key actions in each form of workplace learning is a starting point for developing more effective learning pathways by combining learning practices that integrate the four knowledge sharing behaviours of connecting, consuming, creating and contributing knowledge. Currently workplace learning practices tend to focus on 
connecting and consuming, overlooking creating and contributing. One reason for this could be because learning practices tend to focus on formal learning, overlooking the potential of informal learning. Organisations could benefit from taking a broader look at what constitutes learning practices, bringing work and learning closer together. This could be achieved though recognition of employees' learning through engagement in projects that bring together formal and informal learning by combining different knowledge sharing behaviours.

In conclusion, this study provides a baseline for rethinking combinations of knowledge sharing practices for more effective learning and development in the workplace. While learning at work, employees integrate discreet of knowledge sharing behaviours to form unique learning pathways. This study provides initial insight into the relationship between learning practices and knowledge sharing behaviours and which combinations of these may lead to effective workplace learning. However, a more in-depth analysis is required to understand the potential impact of combining discreet knowledge practices for more effective learning.

\section{REFERENCES}

[1] Lundvall, B-A., Rasmussen, P., \& Lorenz, E. (2008) Education in the Learning Economy: A European Perspective. Policy Futures in Education, 6(6), 681-700. http://dx.doi.org/10.2304/pfie.2008.6.6. $\underline{681}$

[2] IBM (2009) Enterprise of the future study: IBM Global CEO study http://www-935.ibm.com/services/us/gbs/thoughtleadership/ communications.html

[3] Schmidt, H. G., Norman, G. R. and Boshuizen, H. P. A. (1990). A Cognitive Perspectiveon Expertise: Theory and implications, Academic Medicine, 65 (10), 611-621. http://dx.doi.org/10.1097/ 00001888-199010000-00001

[4] Paavola, S., \& Hakkarainen, K. (2005). The knowledge creation metaphor: An emergent epistemological approach to learning. Science and Education, 14(6), 535-557. http://dx.doi.org/10.1007/ $\underline{\text { s11191-004-5157-0 }}$

[5] Engeström, Y. and Middleton (eds), (1996). Cognition and Communication at Work. Cambridge: Cambridge University Press. Expertise: Professional and educational perspectives. Amsterdam: Elsevier.

[6] Edwards, A. (2010), Learning how to know who: Professional learning for expansive practice between organizations Learning across sites, New Perspectives on Learning and Instruction (Eds S. Ludvigsen, A. Lund, I. Rasmussen and R. Saljo)

[7] Nardi, B.A., Whittaker, S. and Schwarz, H(2000) It's not what you know, it's who you know: knowledge work on the web, First Monday, Volume 5, Number 5. http://firstmonday.org/htbin/ cgiwrap/bin/ojs/index.php/fm/article/view/741/650.

[8] Eraut, M (2007) Learning from other people in the workplace. Oxford Review of Education, 33(4), 403-422. http://dx.doi.org/10.1080/03054980701425706

[9] Billett S (2002) Critiquing workplace learning discourses: Participation and continuity at work Studies in the Education of Adults 34 no 1 pp. $56-67$.
[10] Lorenz E. (1996) Collective Learning Processes and the Regional Labour Market. Unpublished Research Note, European Network on Networks, Collective Learning and RTD in RegionallyClustered High Technology SMEs.

[11] Stankevicuite and Jucevicius (2003) The role of universities in the development of regional knowledge-based clusters: The collective learning perspective, European Conference on Educational Research, University of Hamburg, 17-20 September 2003

[12] Davenport, T. (2005). Thinking for a living: How to get better performance and results from knowledge workers. Harvard Business School Press: Boston.

[13] Dorsey, P.A. (2000) Personal Knowledge Management: educational framework for global business Available from http://www.millikin.edu/pkm/pkm istanbul.html

[14] Sellen, A.J., Murphy, R. M., \& Shaw, K. (2002) How knowledge workers use the Web. Proceedings of CHI 2002, Minneapolis, MN. New York: ACM Press, pp. 227-234. Available from http://research.microsoft.com/ asellen/publications/knowledger workers and the web 02.pdf

[15] Karrer (2008) http://www.workliteracy.com/knowledge-workframework

[16] Margaryan, A., Milligan, C., Littlejohn, A., Hendrix, D., and Graeb-Koenneker, S., (2009) Self-regulated learning in the workplace: Enhancing knowledge flow between novices and experts. 4th International Conference on organizational learning, knowledge and capabilities (OLKC), Amsterdam, 26-28 April 2009.

[17] Littlejohn, A., Margaryan, A, and Milligan, C. (2009a). Charting collective knowledge: Supporting self-regulated learning in the workplace. In Proceedings of the 9th IEEE International Conference on Advanced Learning Technologies (ICALT) 2009

[18] Margaryan, A., Littlejohn, A., and Milligan, C., (2009b) Selfregulated learning in the workplace: Enhancing knowledge flow between novices and experts. 13th European Conference for Research on Learning and Instruction, Amsterdam 25-29 August 2009

[19] Cross and Parker (2004) The hidden power of social networks: Understanding how work really gets done in organizations. Boston: Harvard Business School.

[20] Ericsson, K.A., Charness, N., Feltovich, P., \& Hoffman, R. (2006) (Eds.) The Cambridge handbook of expertise and expert performance. New York: Cambridge University Press.

\section{AUTHORS}

Professor A. H. Littlejohn is the Director of the Caledonian Academy and Chair of Learning Technology, Glasgow Caledonian University, UK (allison.littlejohn@gcu.ac.uk).

Dr. C. D. Milligan is a Research Fellow within the Caledonian Academy, Glasgow Caledonian University, UK (colin.milligan@gcu.ac.uk).

Dr. A. Margaryan is a Lecturer in Learning Technology and Work-Related Learning research programme leader within the Caledonian Academy, Glasgow Caledonian University, UK (anoush.margaryan@gcu.ac.uk).

This work was supported by an industry-academia partnership research grant.

Received 23 August 2011. Published as resubmitted by the authors 15 October 2011. 